\begin{tabular}{|c|l|}
\hline Title & $\begin{array}{l}\text { PKA-Dependent Regulation of Synaptic Enhancement between a Buccal Motor Neuron and Its Regul atory Interneuron } \\
\text { in Lymnaea stagnalis }\end{array}$ \\
\hline Author(s) & Nakamura, Hiroshi; Kobay ashi, Suguru; Kojima, Satoshi; U rano, A kihisa; Ito, Etsuro \\
\hline Citation & Zoological Science, 16(3), 387-394 \\
\hline Issue Date & 1999-06 \\
\hline Doc URL & http://hdl.handle.net/2115/32922 \\
\hline Rights & (c) 日本動物学会 /本文献の公開は著者の意思に基づくものである \\
\hline Type & article \\
\hline File Information & 16_387.pdf \\
\hline
\end{tabular}

Instructions for use 


\title{
PKA-Dependent Regulation of Synaptic Enhancement between a Buccal Motor Neuron and Its Regulatory Interneuron in Lymnaea stagnalis
}

\author{
Hiroshi Nakamura, Suguru Kobayashi, Satoshi Kojima, Akihisa Urano \\ and Etsuro Ito* \\ Laboratory of Animal Behavior and Intelligence, Division of Biological Sciences, \\ Graduate School of Science, Hokkaido University, Kita-ku, \\ Sapporo 060-0810, Japan
}

\begin{abstract}
The cerebral giant cell (CGC) is known to play a crucial role in the regulation of feeding response in the pond snail, Lymnaea stagnalis. However, the mechanisms of signal transduction from the CGC to the following buccal motor neurons are not clear. In the present study, we examined whether cyclic AMP (cAMP)-dependent protein kinase (PKA) contributes to enhancement of a monosynaptic connection between the presynaptic CGC and the postsynaptic buccal motor neuron 1 (B1 cell). Injection of CAMP into the CGC or inhibition of phosphodiesterase by isobutylmethylxanthine in the CGC increased the amplitude of excitatory postsynaptic potential (EPSP) in the B1 cell, whereas no changes were detected in the electrical properties of the CGC. The synaptic enhancement in the B1 cell was completely blocked by inhibition of PKA in the CGC but did not require a de novo protein synthesis due to a PKA phosphorylation. The increase in the EPSP amplitude of B1 cell was associated with the increase in the amount of serotonin release from the CGC. These results hence provided the physiological evidence of the direct regulation of a synaptic enhancement by PKA in the CNS of $L$. stagnalis, indicating the completely different mechanism from that in the well-studied siphon- and gill-withdrawal reflex in Aplysia.
\end{abstract}

\section{INTRODUCTION}

The neural system for feeding response in the pond snail, Lymnaea stagnalis, has been studied by physiological, histological and ethological approaches (Yeoman et al., 1996; Kobayashi et al., 1998; Sadamoto et al., 1998; Staras et al., 1998; Nakamura et al., 1999a, b). One of interneurons, which plays a crucial role in the regulation of feeding response, is a cerebral giant cell (CGC). The CGC has a gating and enabling function in the central pattern generator (CPG) for feeding response (Yeoman et al., 1994). The depolarization of the CGC excites and/or inhibits the CPG interneurons, influencing the duration of radula protraction and that of rasping (Yeoman et al., 1996). Some synaptic connections from the CGC to the directly following buccal motor neurons are also involved in the formation of feeding behavior (Kemenes et al., 1986; McCrohan and Audesirk, 1987; Elphich et al., 1995). Further, the CGC receives appetitive and aversive taste signals from the lip and tentacles through their own nerves (Nakamura et al., 1999a, b).

\footnotetext{
* Corresponding author: Tel. +81-11-706-2615; FAX. +81-11-706-4448. E-mail. eito@sci.hokudai.ac.jp
}

The regulation of feeding response is varied via some synaptic enhancement in the feeding circuitry by a conditioning. L. stagnalis can be readily conditioned to inhibit feeding response to a previously appetitive stimulus, when repeatedly and specifically paired with an aversive reinforcement (Kojima et al., 1996, 1997, 1998; Yamanaka et al., 1999). This is referred to as a 'conditioned taste aversion'. In this conditioning, inhibitory postsynaptic potential (IPSP) in a CPG interneuron by activation of the CGC was larger and lasted longer in the conditioned snails than in the control snails (Kojima et al., 1997). However, the mechanisms of signal transduction in this synaptic enhancement have not yet been determined. In general, the studies of the second-messenger system in $L$. stagnalis have not been advanced very far (Dreijer and Kits, 1995). Only the work by McCrohan and Gillette (1988) suggested that cyclic AMP (CAMP) is a candidate of the second messenger in the CGC by demonstrating the appearance of $\mathrm{Na}^{+}$current by the cAMP injection. The roles of cAMP have been extremely studied in synaptic enhancements in Aplysia. Intracellular CAMP in the sensory neuron plays an important role in the siphon- and gill-withdrawal reflex (Ocorr et al., 1985; Pollock et al., 1985; Schacher et al., 1988; Klein, 1993). In addition, the cAMP-dependent protein kinase (PKA) pathway and the CAMP-response element binding protein (CREB) in 
the siphon- and gill-withdrawal reflex of Aplysia are known to act critically in the consolidation of short-term changes in the synaptic plasticity into long-term memory (Dash et al., 1990; Kaang et al., 1993; Martin et al., 1997). Taken together, the effects of cAMP on the synaptic plasticity should be first of all examined in gastropod neurons, such as the CGC in $L$. stagnalis.

The buccal motor neuron 1 (B1 cell) is a salivary gland motor neuron which receives a monosynaptic excitatory input from the CGC (Benjamin et al., 1979; McCrohan and Benjamin, 1980). The firing of the B1 cell definitely synchronizes with the radula-protraction phase of feeding cycle (Rose and Benjamin, 1979). The excitation of the B1 cell by activation of the CGC is thus considered to evoke secretion of saliva and to be important for harmonious behavior in feeding.

In the present study, we examined a synaptic enhancement by cAMP and PKA between the CGC and the B1 cell in the isolated central nervous system (CNS) of $L$. stagnalis. First, the changes in the excitatory postsynaptic potentials (EPSPs) in the B1 cell were examined as the synaptic enhancement between the CGC and the B1 cell, when CAMP was injected into the CGC. Second, to confirm that this synaptic enhancement was induced by the increase in intracellular cAMP concentration, a phosphodiesterase inhibitor was applied to the CGC. Third, whether PKA activated by CAMP is involved in the synaptic enhancement was studied by a competitive antagonist of cAMP. Fourth, the effect of de novo protein synthesis was examined on the synaptic enhancement by protein synthesis inhibitors. Finally, as taking into account that the CGC is serotonergic (Boer et al., 1984; Tuersley and McCrohan, 1988; Yeoman et al., 1996; Sadamoto et al., 1998), the $B 1$ cell was treated with serotonin antagonists to test the contribution of amount of serotonin release to the synaptic enhancement.

\section{MATERIALS AND METHODS}

\section{CNS preparations}

Specimens of Lymnaea stagnalis, originally supplied from Vrije Universiteit in Amsterdam, were kept in tap water and fed on lettuce on a $12: 12$ light-dark cycle at $20^{\circ} \mathrm{C}$. The CNSs were isolated from adults with the shell length of $2-2.5 \mathrm{~cm}$ after anesthetization by immersion in $25 \%$ Listerine ${ }^{\circledR}$ for 5 min. The isolated CNS was immersed in Lymnaea saline and pinned in a Sylgard-lined dish for recording. Lymnaea saline contained: $24 \mathrm{mM} \mathrm{NaCl}, 2 \mathrm{mM} \mathrm{KCl}, 2 \mathrm{mM} \mathrm{MgCl}_{2}, 4$ $\mathrm{mM} \mathrm{CaCl}, 0.3 \mathrm{mM}$ D-glucose, $0.1 \mathrm{mM} \mathrm{NaH}_{2} \mathrm{PO}_{4}$, and $35.4 \mathrm{mM}$ HEPES-NaOH (pH 7.9). Then the CNS was incubated with protease ( $1 \mathrm{mg} / \mathrm{ml}$, type XXIV, Sigma, St. Louis, MO) for $10 \mathrm{~min}$ and washed out thoroughly with the saline. To stabilize the excitation of the CNS after dissection, the preparation was kept in the recording dish filled with the saline at $4^{\circ} \mathrm{C}$ for $2 \mathrm{hr}$ before intracellular recording.

\section{Intracellular recording}

The B1 cell and the CGC were impaled with glass microelectrodes filled with $2 \mathrm{M}$ potassium acetate, giving tip resistances of 20-60 M $\Omega$. The EPSP evoked in the B1 cell was amplified with an intracellular recording amplifier (NEURO DATA, Model IR-283, New York, NY), monitored with an oscilloscope (TEKTRONIX, 2213, Wilsonville, OR), and recorded with a computer (Quark, IBM-compatible type, Sapporo, Japan). A train of 10 spikes in the CGC, which was produced by a current injection for $1 \mathrm{sec}$, evoked a large compound EPSP in the B1 cell as a superposition of 10 individual EPSPs. Only the B1 cells that showed responses of less than $15 \mathrm{mV}$ amplitude as the initial compound EPSPs were used in the present study. The time course of the EPSP enhancement after the cAMP injection and that after the 5'AMP injection consist of the data obtained from six and three preparations, respectively. The combinations of the data recorded in the same preparation were as follows: 0 and $0.5 \mathrm{hr}, 0$ and 1 and $2 \mathrm{hr}, 0$ and $3 \mathrm{hr}, 0$ and $6 \mathrm{hr}$, and 0 and $24 \mathrm{hr}$. The data at $0 \mathrm{hr}$ were recorded before drug applications. Therefore, the electrodes were changed with the electrodes for injection or removed until the next recording time.

\section{Drug applications}

Either cAMP (Sigma) or 5'AMP (Sigma), which was filled in a glass microelectrode $(80-120 \mathrm{M} \Omega$ as a $200 \mathrm{mM}$ solution dissolved in $20 \mathrm{mM}$ Tris buffer ( $\mathrm{pH} 7.5$ ), was injected into the CGC by passing hyperpolarizing current pulses (50 msec on, $50 \mathrm{msec}$ off) of $4 \mathrm{nA}$ for $20 \mathrm{~min}$. This injection period was decided by conferring with the work of Aplysia (Scholz and Byrne, 1988). Isobutylmethylxanthine (IBMX, Sigma), Rp-adenosine 3',5'-cyclic monophosphothioate (Rp-cAMPS, Sigma), anisomycin (Sigma), and cycloheximide (Sigma) were applied in the recording chamber. The concentrations and application periods of three drugs were specified in each experiment. IBMX is a cAMP phosphodiesterase inhibitor. Rp-cAMPS is a cAMP competitive antagonist for PKA. Anisomycin and cycloheximide are protein synthesis inhibitors.

When the isolated CNS except the buccal ganglia was incubated with these drugs, the buccal ganglia were completely partitioned off by a silicone grease wall. Thus, the B1 cell was not affected by these drugs. When the EPSP in the B1 cell was recorded, IBMX, but not Rp-cAMPS nor the protein synthesis inhibitors, was washed out to avoid the bursting of the CGC. Neither Rp-cAMPS nor the protein synthesis inhibitors elicited the bursting of the CGC. Ketanserin (RBI, Natick, MA) and 3-tropanyl-3,5-dichlorobenzoate (MDL 72222, RBI), which are an antagonist for the metabotropic serotonin $\left(5-\mathrm{HT}_{1}\right.$ and $5-$ $\mathrm{HT}_{2}$ ) receptor and that for the ionotropic serotonin $\left(5-\mathrm{HT}_{3}\right)$ receptor, respectively, were applied onto the whole CNS.

\section{Analysis of data}

The changes in the amplitudes of EPSPs were normalized by the results at the start of recording $(0 \mathrm{hr})$. The data were presented by mean \pm SEM. The Student's $t$ test (two-tailed) was used to test the significance of the EPSP changes by injection or application of drugs. In dose-response of the EPSP amplitude to applied MDL 72222, the half maximum blockade was estimated by the curve fitting to the data points with Boltzmann equation, which was presented by $y=\left(A_{1}-\right.$ $\left.A_{2}\right) /\left[1+\exp \left\{\left(x-x_{0}\right) / x\right\}\right]+A_{2} . y$ and $x$ indicate the EPSP amplitude and the concentration of the drug, respectively. $A_{1}, A_{2}, x_{0}$, and $x$ are the initial value of $y$, the final value of $y, x$ value at a half decay of $y$, and the width of $x$ value during a decay of $y$, respectively. The software for this curve fitting was 'Microcal Origin' (ver. 4.10, Microcal Software, Northanpton, MA).

\section{RESULTS}

\section{Synaptic enhancement between a buccal motor neuron and its regulatory interneuron by cAMP}

When cAMP was injected into the CGC, we observed the firing of the CGC. This firing, however, disappeared $30 \mathrm{~min}$ after the injection. We measured the changes in the EPSPs in the $\mathrm{B} 1$ cell by activation of the CGC after the CAMP injection. Three hours after the onset of CAMP injection, the CGC was depolarized by a constant current $(1.0 \mathrm{nA}, 500 \mathrm{msec})$ to fire 
A

cAMP

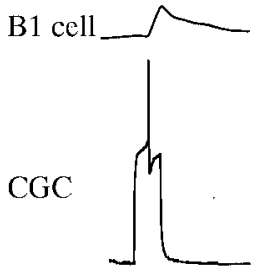

5 AMP

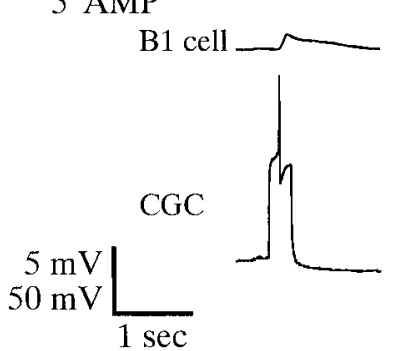

B
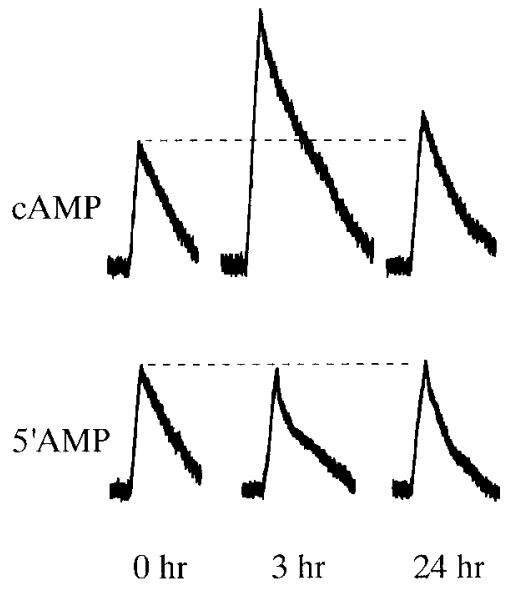

$5 \mathrm{mV}{\underset{5 \mathrm{sec}}{L}}$
$\mathrm{C}$

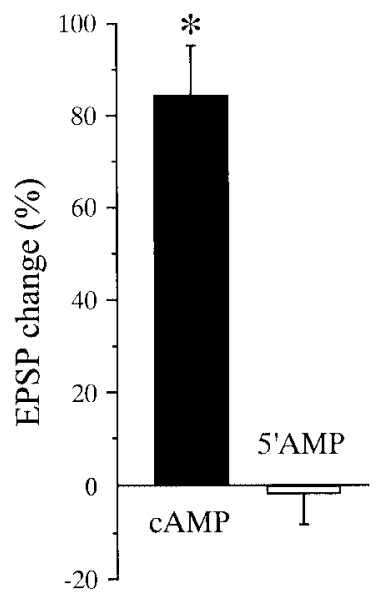

Fig. 1. Synaptic enhancement between a buccal motor neuron (B1 cell) and its regulatory interneuron (CGC) injected with cAMP. (A) A single EPSP in the B1 cell evoked by firing an action potential in the cAMP-injected CGC with a constant current depolarizing pulse was about twice larger than that by an activation of the 5'AMP-injected CGC. Both EPSPs were recorded $3 \mathrm{hr}$ after the onset of injection and filtered with FFT. The injection period was $20 \mathrm{~min}$. (B) A train of 10 spikes in the CGC evoked a large compound EPSP in the B1 cell, providing the clearer effects of cAMP. The effect of CAMP injection into the CGC was produced $3 \mathrm{hr}$ later and extinguished in $24 \mathrm{hr}$. No significant changes were observed by the 5'AMP injection. (C) The changes in the amplitudes of the compound EPSPs in the B1 cells were summarized. The data were recorded $3 \mathrm{hr}$ after the onset of injections of CAMP and 5'AMP into the CGC. * indicates $p<0.001$.

an action potential, offering a single EPSP in the B1 cell (Fig. 1A). This single EPSP in the preparation of the cAMP-injected CGC was about twice larger than that in the preparation of the 5'AMP-injected CGC (Fig. 1A). Because the single EPSP in the B1 cell was very small $(<3 \mathrm{mV})$, we often failed to detect it depending on the preparation. We thus noticed a large compound EPSP in the B1 cell that was evoked by a train of 10 spikes in the CGC. The large compound EPSPs provided very clear effects of cAMP. The effect of cAMP injection was apparent $3 \mathrm{hr}$ later and extinguished in $24 \mathrm{hr}$ (Fig. 1B), while no significant changes were observed in the 5'AMP-injected preparations. The changes in the amplitudes of compound EPSPs in the B1 cells were summarized in Fig. 1C. The amplitudes of the compound EPSPs $3 \mathrm{hr}$ after the onset of the cAMP injection $(n=8)$ were significantly greater $(p<0.001)$ than that in the preparations of the 5'AMP injection $(n=7)$.

To examine the time-dependency of the effect of cAMP, we measured the amplitudes of the compound EPSPs at seven intervals $(0,0.5,1,2,3,6$, and $24 \mathrm{hr})$ after the onset of the cAMP injection or at four intervals $(0,0.5,3$, and $24 \mathrm{hr})$ after the onset of the 5'AMP injection into the CGC (Fig. 2, $\mathrm{n}=$ at least 7). Both EPSPs by the CAMP injection and the 5'AMP injection were slightly enhanced at $0.5 \mathrm{hr}$, but not presented any significant differences. The facilitatory effect of cAMP on the synaptic transmission between the CGC and the $\mathrm{B} 1$ cell was thus produced $3 \mathrm{hr}$ later. The effect persisted for more than $6 \mathrm{hr}(p<0.001 \mathrm{vs}$. all the data for 5'AMP) and extinguished in $24 \mathrm{hr}$. Thus, the compound EPSP $3 \mathrm{hr}$ after the

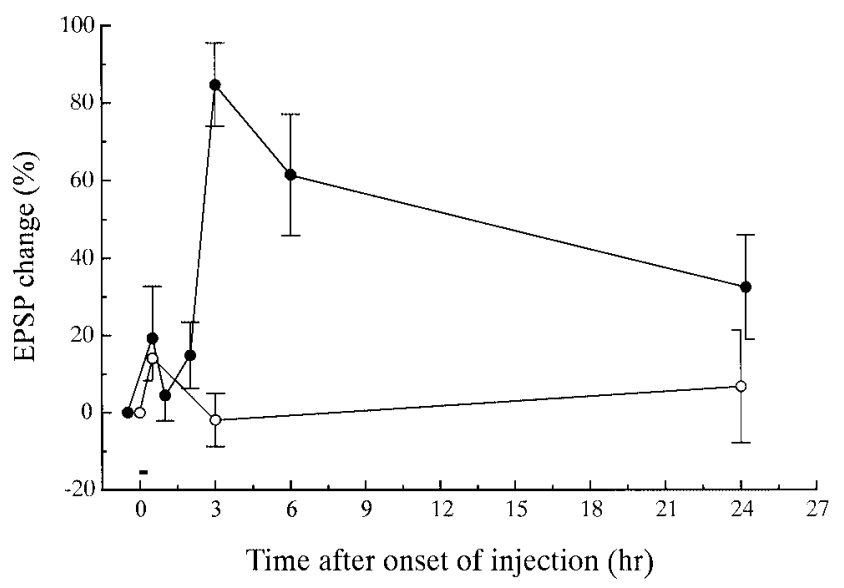

Fig. 2. Time course of the EPSP enhancement in the B1 cell induced by the CAMP injection into the CGC. The solid circles and the open circles show the data of the cAMP injection and the 5'AMP injection, respectively. The synaptic enhancement persisted for more than $6 \mathrm{hr}$ after the injection of cAMP, and almost recovered to the initial amplitude in $24 \mathrm{hr}$. Bar, the injection period of $20 \mathrm{~min}$.

cAMP or 5'AMP injection was monitored in the following experiments.

\section{Changes in excitability of the CGC by cAMP}

To test the effect of CAMP on the excitability of the CGC, we compared the input resistance, the resting potential, the duration of the current-evoked spike and the spontaneous 
Table 1. Electrical properties of cAMP- and 5'AMP-injected CGCs $3 \mathrm{hr}$ after the onset of injection

\begin{tabular}{lcc}
\hline & cAMP $(\mathrm{n}=8)$ & 5'AMP $(\mathrm{n}=7)$ \\
\hline Input resistance $(\mathrm{M} \Omega)$ & $54 \pm 12$ & $46 \pm 7$ \\
Resting potential $(\mathrm{mV})$ & $-55 \pm 3$ & $-56 \pm 2$ \\
Spontaneous spike duration* $(\mathrm{msec})$ & $12.1 \pm 0.5$ & $11.5 \pm 0.7$ \\
Evoked spike duration* $(\mathrm{msec})$ & $13.0 \pm 0.7$ & $14.2 \pm 0.9$ \\
Depth of afterhyperpolarization & $9.1 \pm 0.7$ & $9.0 \pm 0.6$ \\
in the spontaneous spike (mV) & & \\
$\quad$ Duration of afterhyperpolarization & $94.4 \pm 12.0$ & $90.6 \pm 12.4$ \\
in the spontaneous spike * $(\mathrm{msec})$ & &
\end{tabular}

Values are mean \pm SEM.

${ }^{*}$ indicates the width at half maximum.

spike, and the depth and duration of the afterhyperpolarization in the spontaneous spike between the cAMP-injected CGCs and the 5'AMP-injected CGCs. We found no significant differences in these values between the CAMP- and the 5'AMPinjected CGCs (Table 1). The data were recorded $3 \mathrm{hr}$ after the onset of injections.

\section{Effect of IBMX on the EPSP in the B1 cell}

By using IBMX, we proved that the increase in intracellular CAMP concentration in the CGC can enlarge the compound EPSP in the B1 cell. An incubation with IBMX caused the spontaneous firing of the CGC which presented the same pattern as observed by the cAMP injection. The effective concentration of IBMX was determined to be $300 \mu \mathrm{M}$ by taking the doseresponse to this firing of the CGC (data not shown). The incubation with $300 \mu \mathrm{M}$ IBMX on the cerebral ganglion for $20 \mathrm{~min}$ that was the identical period as the CAMP-injection period did not mimic the enlargement of the compound EPSP in the B1 cell, even if the data were recorded $3 \mathrm{hr}$ later (Fig. $3 \mathrm{~A})$. The 20-min incubation with IBMX, together with the cAMP injection, increased the amplitude of the compound EPSP $3 \mathrm{hr}$ after the treatment. This increase was similar to that by the cAMP injection only (see Figs. $1 B$ and $3 A$ ). The 3-hr incubation with IBMX did mimic the large compound EPSP $3 \mathrm{hr}$ after the incubation (Fig. 3A). The results summarized in Fig. 3B show that the significantly larger EPSPs $(p<0.001)$ in the B1 cells were elicited by the long-term ( $3 \mathrm{hr}$ ) application of IBMX $(n=7)$ than by the short-term (20 $\min )$ application $(n=7)$.

\section{Effect of PKA inhibitor on the EPSP in the B1 cell}

We applied Rp-cAMPS onto the cerebral ganglion, in which the CGC was injected with CAMP, for $4 \mathrm{hr}$ that included 1-hr pre-incubation period before the CAMP-injection. The effective concentration $(500 \mu \mathrm{M})$ of Rp-cAMPS, which was reported in the work for Aplysia by Ghirardi et al. (1992), blocked the increase in the EPSP in the B1 cell, and further reduced it below the initial level (Fig. 4A). The results summarized in Fig. 4B show that the significantly smaller EPSPs $(p<0.01)$ in
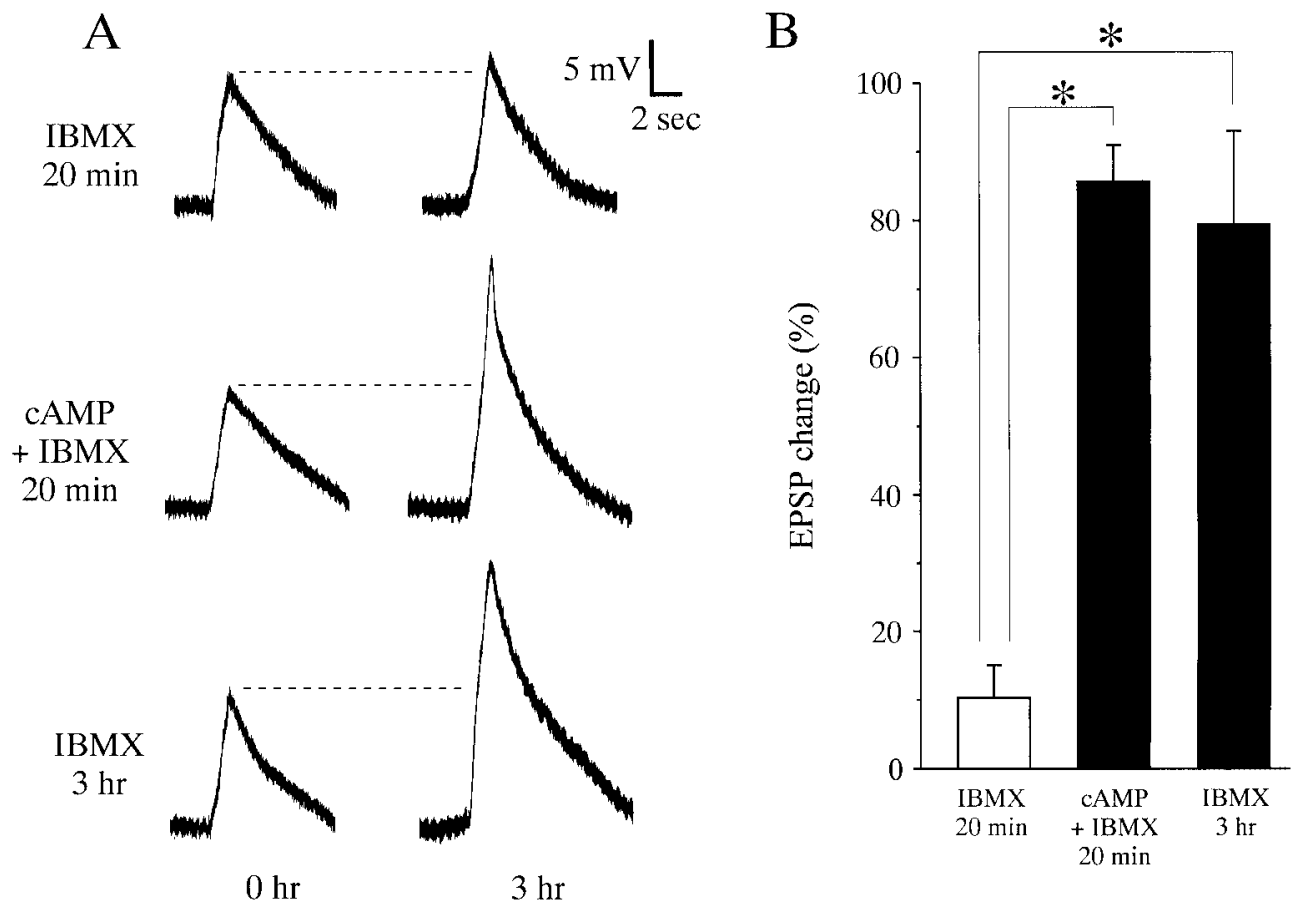

Fig. 3. Effect of IBMX on the EPSP enhancement in the B1 cell. (A) The IBMX application on the cerebral ganglia during the identical period (20 $\mathrm{min}$ ) as that for the CAMP injection did not induce the EPSP enhancement in the B1 cell when recorded $3 \mathrm{hr}$ after the onset of treatment. Both the IBMX application and the CAMP injection at the same time elicited the large enhancement. The long-term ( $3 \mathrm{hr}$ ) application of IBMX enhanced the EPSP in the B1 cell to the same level as the cAMP injection. (B) The changes in the amplitudes of the compound EPSPs in the B1 cells were summarized. The data were recorded $3 \mathrm{hr}$ after the onset of IBMX application on the cerebral ganglia and/or that of cAMP injection into the CGC. * indicates $p<0.001$. 

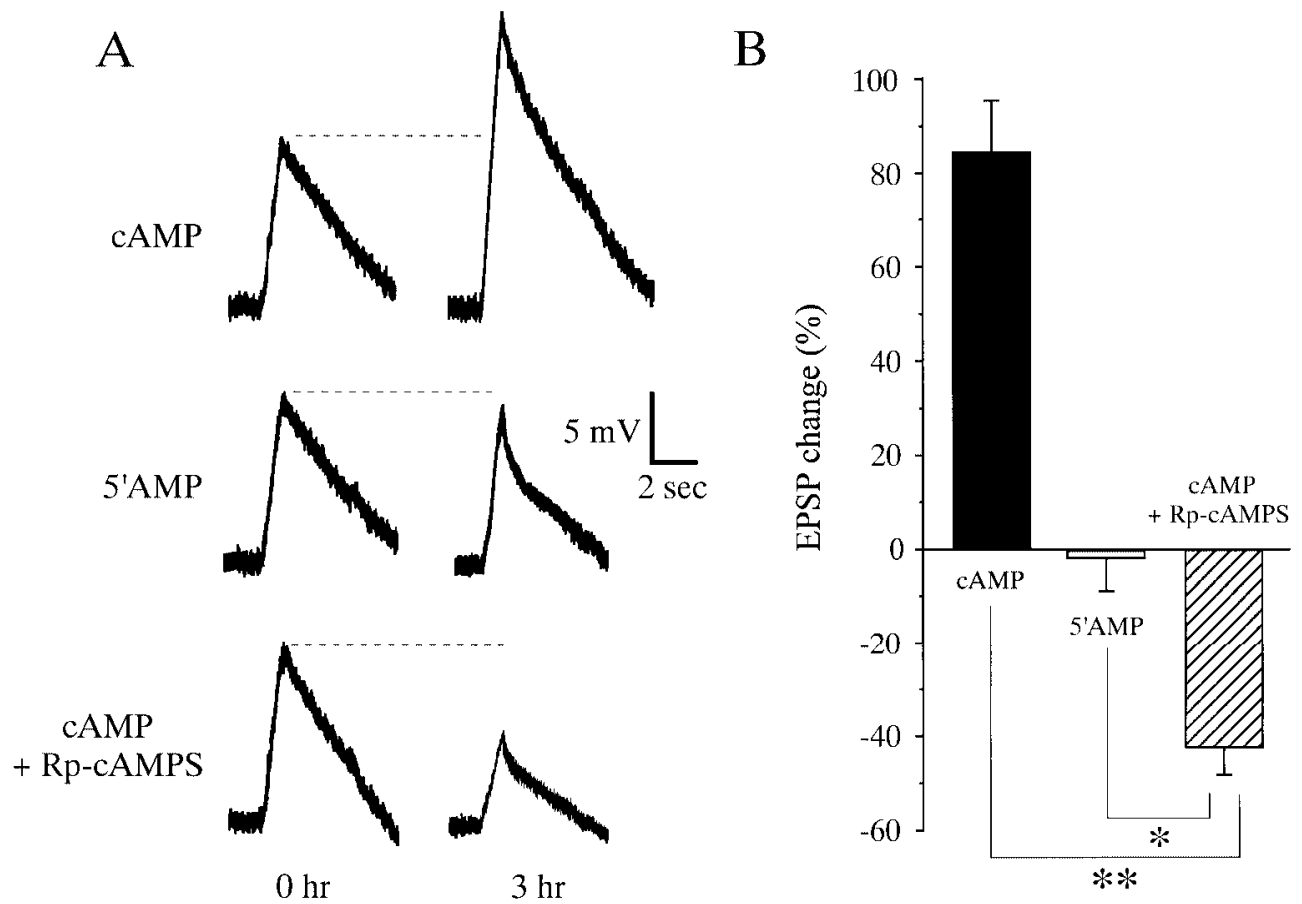

Fig. 4. Blockade of the increase in EPSP amplitude in the B1 cell by Rp-cAMPS application on the cerebral ganglia. (A) Even though cAMP was injected into the CGC, the long-term (4 hr) treatment of Rp-cAMPS, including the pre-incubation period of $1 \mathrm{hr}$, prevented the increase in EPSP in the B1 cell, and further suppressed it under the control level of 5'AMP injection. (B) The EPSP changes in the B1 cell were summarized. ${ }^{*}$ and ${ }^{* *}$ indicate $p<0.01$ and $p<0.001$, respectively.

A

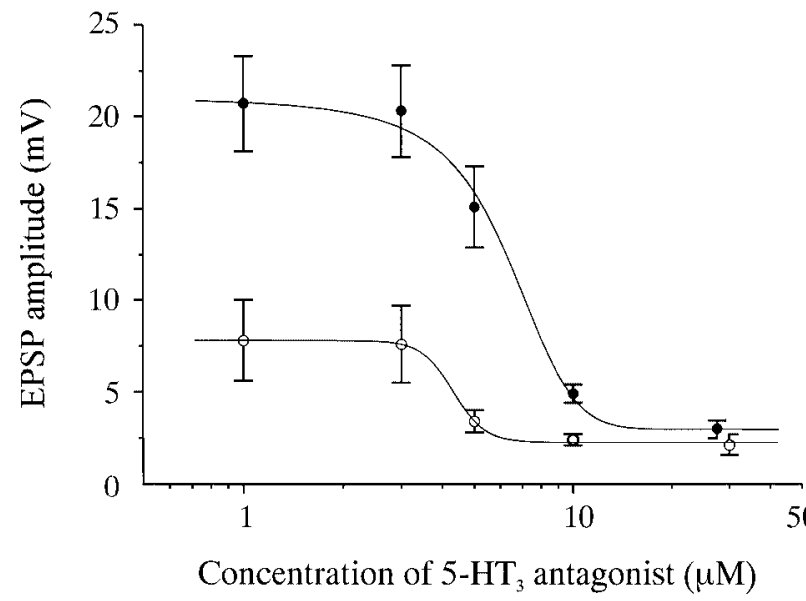

$\mathrm{B}$

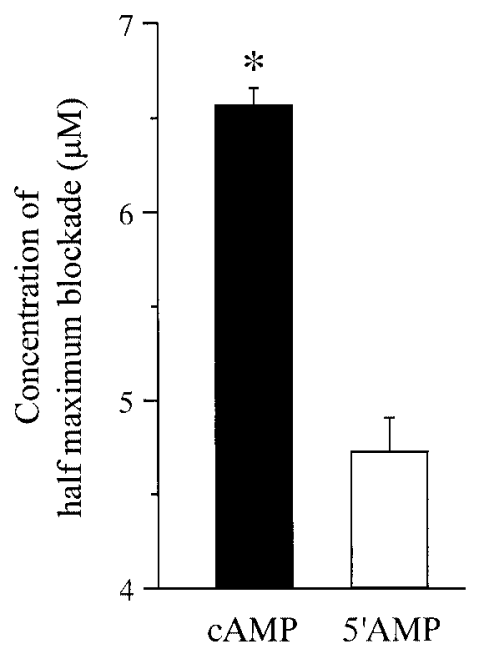

Fig. 5. Dose-response of the EPSP amplitude in the $\mathrm{B} 1$ cell to $5-\mathrm{HT}_{3}$ antagonist. (A) The amplitudes of the compound EPSPs in the $\mathrm{B} 1 \mathrm{cell}$ were recorded $3 \mathrm{hr}$ after the onset of injection of cAMP (solid circles) or 5'AMP (open circles) into the CGC. During the last $30 \mathrm{~min}$ of this $3 \mathrm{hr}$, 5- $\mathrm{HT}_{3}$ antagonist, MDL 72222, was applied on the whole CNS. (B) The concentrations of MDL 72222 for the half maximum blockade were summarized. The concentration for half maximum blockade for the EPSP evoked by activation of the cAMP-injected CGC was significantly higher $\left({ }^{*} p<0.001\right)$ than that for the 5'AMP-injected CGC.

the B1 cells were elicited by the CAMP injection into the CGCs together with the application of Rp-cAMPS $(n=5)$ than by the 5'AMP injection into the CGCs without Rp-cAMPS $(n=7)$. The electrical properties of the CGC were not changed by the incubation of Rp-cAMPS (data not shown).

\section{Effect of protein synthesis inhibitor on the EPSP in the B1 cell}

We incubated the cerebral ganglion, in which the CGC was injected with cAMP, together with the protein synthesis inhibitor (anisomycin or cycloheximide) for $4 \mathrm{hr}$ that included 
1-hr pre-incubation period before the cAMP injection. By the cAMP injection, the EPSPs were enlarged with an increase of $85 \% \pm 8 \%(n=3)$ and $76 \% \pm 4 \%(n=3)$ even in the presence of $30 \mu \mathrm{M}$ anisomycin and $100 \mu \mathrm{M}$ cycloheximide, respectively. These increases were the same as that by the cAMP injection only (see Fig. 1B). The concentrations of the applied drugs were three times higher than those for the cultured cells of Aplysia (Montarolo et al., 1986; Ghirardi et al., 1995) for a good penetration through the sheath of ganglia.

\section{Dose-response of the EPSP in the B1 cell to serotonin antagonist}

Wolcourt-Ambakederemo and Winlow (1994a, b, 1995) identified two metabotropic subtypes $\left(5-\mathrm{HT}_{1}\right.$ - and $5-\mathrm{HT}_{2}$-like receptors) and one ionotropic subtype (5- $\mathrm{HT}_{3}$-like receptor) of serotonin receptors in the CGC and some motor neurons (B1, B2, and B4 cells) of L. stagnalis. To determine if the increase in the amplitude of the compound EPSP in the B1 cell by cAMP is due to the increase in the serotonin release from the CGC, we examined the dose-responses of the EPSP amplitudes to the antagonists, ketanserin and MDL 72222. If the amount of released serotonin increases, the dose-response curve must shift. These antagonists were applied onto the whole CNS for 30 min before the EPSP recording. The large compound EPSP in the B1 cell by cAMP was not suppressed by $100 \mu \mathrm{M}$ ketanserin (data not shown). This concentration was considered to be effective from the results of Wolcourt-Ambakederemo and Winlow (1994b), if the metabotropic serotonin receptors acted in the CGC-B1 cell synapse. On the other hand, the EPSP was decreased by MDL 72222 in a dose-dependent manner, and the dose-response for the preparations in the synaptic enhancement was shifted (Fig. 5A). The EPSP amplitudes in the preparations injected by CAMP and the 5'AMP were saturated to decrease by the applications of about $10 \mu \mathrm{M}$ and $5 \mu \mathrm{M}$ of MDL 72222 , respectively (Fig. 5A). Figure $5 \mathrm{~B}$ shows the concentrations of MDL 72222 for the half maximum blockade for the EPSPS. The concentrations for half maximum blockade for the EPSPS evoked by activation of the CAMP-injected CGCs $(n=3)$ were significantly higher $(p<0.001)$ than for the 5'AMP-injected CGCs $(n=3)$.

\section{DISCUSSION}

We demonstrated that the synaptic enhancement as the increase in the amplitude of the compound EPSP in the buccal motor neuron 1 (B1 cell) by activation of its regulatory interneuron (cerebral giant cell, CGC) in which the intracellular cAMP concentration was elevated by the cAMP injection or the phosphodiesterase inhibition (Figs. 1 and 3). The characteristics of this synaptic enhancement were as follows. (1) The compound EPSP became the largest $3 \mathrm{hr}$ after the onset of CAMP injection, and its enhancement persisted for more than $6 \mathrm{hr}$ (Fig. 2). (2) This synaptic enhancement was not caused as a result of the prolongation of the action potential in the presynaptic neuron, the CGC. (3) The PKA inhibitor completely blocked the effect of cAMP on the compound EPSP and, further, significantly reduced the amplitude of the compound EPSP below the control level (Fig. 4). (4) The synaptic enhancement was independent from a de novo protein synthesis. (5) The dose-response of the compound EPSP in the B1 cell to the antagonist for the ionotropic serotonin receptor was shifted for the preparations in the synaptic enhancement (Fig. 5).

The synaptic enhancement by cAMP in the present study seemed to be similar to the case in Aplysia. However, there are two remarkable differences between these two preparations: (1) the prolongation of an action potential in a presynaptic cell and (2) a de novo protein synthesis. The short- and long-term facilitation in Aplysia caused by cAMP cascade required the prolongation of an action potential and a de novo protein synthesis, respectively (Siegelbaum et al., 1982; Sweatt and Kandel, 1989; Hochner and Kandel, 1992; Schacher et al., 1993; O'Leary et al., 1995; Sugita et al., 1997; Abel and Kandel, 1998). Even in the CNS of Hermissenda in which intracellular $\mathrm{Ca}^{2+}$ plays an important role in the signal transduction (Alkon et al., 1992; Ito et al., 1994), the longlasting depolarization due to a reduction in $\mathrm{K}^{+}$-channel conductance and the increase in specific mRNA were reported in the synaptic enhancement in a classical conditioning (Alkon et al., 1985; Nelson and Alkon, 1990). To gain a deeper insight into the excitability of the presynaptic CGC, the duration of the current-evoked and the spontaneous spikes at $30 \%$ and $70 \%$ from their bottoms were also examined (see the methods in Klein (1993). We found no changes in the results after the CAMP injection (data not shown). Because the data were recorded in the somata of the CGCs, we cannot role out a possibility of changes in action potential in the synaptic terminal.

The $500 \mu \mathrm{M}$ concentration of Rp-cAMPS is known to give the maximal level of inhibition of the enhancement of sensorimotor synapses in Aplysia (Ghirardi et al., 1992). The enhanced EPSP amplitudes in these systems, however, were only reduced to the initial level, but not below it. Therefore, the results using Rp-cAMPS shown in Fig. 4 strongly suggest that the activation of PKA in the CGC is required to even evoke the usual EPSP in the B1 cell. In other words, a physiological substrate phosphorylated by PKA always works in the process of neurotransmitter release. One possible explanation for this phenomenon is a cAMP-dependent regulation of the synaptic vesicle fusion. Recently, some works for cAMP-dependent long-term potentiation in the rat hippocampus reported that the PKA phosphorylation of a synaptic vesicle protein such as rabphilin regulates the synaptic vesicle fusion in presynaptic terminal, causing an increase in neurotransmitter release (Castillo et al., 1997; Lonart and Südhof, 1998). This synaptic plasticity did not need the prolongation of the presynaptic action potential or the de novo protein synthesis. We should examine the phosphorylation of rabphilin-like proteins in the CGC in a future work.

If the PKA activation is directly involved in the synaptic vesicle fusion, the period of $3 \mathrm{hr}$ to express the increase in the 
EPSP amplitude (Fig. 2) is considered to be the axonal diffusion time of cAMP from the cell body to the synaptic terminal in the CGC. When a fluorescent dye, lucifer yellow ( $M W=$ 457), was injected into the cell body of CGC, its axonal diffusion time to reach the synaptic terminal took $4 \mathrm{hr}$ at $4^{\circ} \mathrm{C}$. Because cAMP has the comparable molecular weight ( $\mathrm{MW}=$ 351 ), the period of $3 \mathrm{hr}$ may be reasonable to produce the maximal effect on the EPSP amplitude in the B1 cell.

We injected cAMP into the CGC by using a hyperpolarizing current, and applied the drugs for cAMP cascade onto only the ganglia including the CGC. That is, we never stimulated the postsynaptic B1 cell. These conditions strongly suggest that Fig. 5 shows the increase in the amount of serotonin release from the presynaptic CGC after the cAMP injection, but not the changes in the sensitivity or the density of serotonin receptors in the postsynaptic B1 cell. In addition, because the electrical properties, such as the input resistance etc, were not changed in the CGC after the CAMP injection, the appearance of new release sites of serotonin in the presynaptic terminal was not supposed. Only the antagonist for the ionotropic serotonin receptor could suppress the EPSP amplitude in the B1 cell. This result seems to reflect the difference in the physiological properties of the subtypes of serotonin receptor. Wolcourt-Ambakederemo and Winlow (1994b, 1995) reported that the antagonist for ionotropic receptor and that for metabotropic receptor reduced the depolarizing and the hyperpolarizing responses, respectively, in the CNS of $L$. stagnalis by the application of serotonin.

The increase in intracellular concentration of CAMP in the CGC has not yet been confirmed by taste stimulation. The CGC has metabotropic serotonin receptors which activate adenylyl cyclase (Wolcourt-Ambakederemo and Winlow, 1994a, b) and receives taste signals from the sensory neurons in the lip and tentacles (Kemenes et al., 1986; McCrohan and Audesirk, 1987; Nakamura et al., 1999a, b). Because the lip nerves include serotonergic fibers (Sadamoto et al., 1998), some of the sensory neurons for taste are considered to be serotonergic. Therefore, the increase in CAMP in the CGC possibly occurs during feeding.

In conclusion, the synaptic enhancement elicited by cAMP-PKA cascade was first observed in the synaptic connection between the buccal motor neuron and its regulatory interneuron in the feeding circuitry of $L$. stagnalis. The cellular mechanism of this synaptic enhancement included the increase in the amount of serotonin release from the presynaptic interneuron which was regulated by the PKA phosphorylation, but not required any changes in the electrical properties or a de novo protein synthesis in the presynaptic interneuron. Therefore, the mechanism of the synaptic enhancement in the present study was completely different from the well-studied mechanisms in Aplysia and Hermissenda. The present results provided the physiological evidence of the direct regulation of a synaptic enhancement by PKA.

\section{ACKNOWLEDGMENTS}

This work was partly supported by Grants-in-Aid from the Ministry of Education, Science, Sports and Culture of Japan to A.U. and E.I.

\section{REFERENCES}

Abel T, Kandel E (1998) Positive and negative regulatory mechanisms that mediate long-term memory storage. Brain Res Rev 26: $360-378$

Alkon DL, Sakakibara M, Forman R, Harrigan J, Lederhendler I, Furley $\mathrm{L}$ (1985) Reduction of two voltage-dependent $\mathrm{K}^{+}$currents mediates retention of a learned association. Behav Neural Biol 44: 278-300

Alkon DL, Sánchez-Andrés JV, Ito E, Oka K, Yoshioka T, Collin C (1992) Long-term transformation of an inhibitory into an excitatory GABAergic synaptic response. Proc Natl Acad Sci USA 89: 11862-11866

Benjamin PR, Rose RM, Slade CT, Lacy MG (1979) Morphology of identified neurons in the buccal ganglia of Lymnaea stagnalis. J Exp Biol 80: 119-135

Boer HH, Schot LP, Steinbusch HW, Montagne C, Reichelt D (1984) Co-existence of immunoreactivity to anti-dopamine, anti-serotonin, anti-vasotocin in cerebral giant neuron of pond snail Lymnaea stagnalis. Cell Tissue Res 238: 411-412

Castillo PE, Janz R, Südhof TC, Tzounopoulos T, Malenka RC, Nicoll RA (1997) Rab3A is essential for mossy fiber long-term potentiation in the hippocampus. Nature 388: 590-593

Dash P, Hochner B, Kandel ER (1990) Injection of the cAMP-responsive element into the nucleus of Aplysia sensory neurons blocks long-term facilitation. Nature 345: 718-721

Dreijer AMC, Kits KS (1995) Multiple second messenger routes enhance two high-voltage-activated calcium currents in molluscan neuroendocrine cells. Neuroscience 64: 787-800

Elphich MR, Kemenes G, Staras K, O'Shea M (1995) Behavioral role for nitric oxide in chemosensory activation of feeding in a mollusc. J Neurosci 15: 7653-7664

Ghirardi M, Braha O, Hochner B, Montarolo PG, Kandel ER, Dale N (1992) Roles of PKA and PKC in facilitation of evoked and spontaneous transmitter release at depressed and nondepressed synapses in Aplysia sensory neurons. Neuron 9: 479-489

Ghirardi M, Montarolo PG, Kandel ER (1995) A novel intermediate stage in the transition between short- and long-term facilitation in the sensory to motor neuron synapse of Aplysia. Neuron 14:413420

Hochner B, Kandel ER (1992) Modulation of a transient $\mathrm{K}^{+}$current in the pleural sensory neurons of Aplysia by serotonin and cAMP: implications for spike broadening. Proc Natl Acad Sci USA 89: $11476-11480$

Ito E, Oka K, Collin C, Schreurs BG, Sakakibara M, Alkon DL (1994) Intracellular calcium signals are enhanced for days after Pavlovian conditioning. J Neurochem 62: 1337-1344

Kaang B-K, Kandel ER, Grant SGN (1993) Activation of cAMP-responsive genes by stimuli that produce long-term facilitation in Aplysia sensory neurons. Neuron 10: 427-435

Kemenes G, Elliott CJH, Benjamin PR (1986) Chemical and tactile inputs to the Lymnaea feeding system: Effects on behaviour and neural circuitry. J Exp Biol 122: 113-137

Klein M (1993) Differential cyclic AMP dependence of facilitation at Aplysia sensorimotor synapses as a function of prior stimulation: augmentation versus restoration of transmitter release. J Neurosci 13: $3793-3801$

Kobayashi S, Kojima S, Yamanaka M, Sadamoto H, Nakamura $H$, Fujito Y, Kawai R, Sakakibara M, Ito E (1998) Operant conditioning of escape behavior in the pond snail, Lymnaea stagnalis. 
Zool Sci 15: 683-690

Kojima S, Yamanaka M, Fujito Y, Ito E (1996) Differential neuroethological effects of aversive and appetitive reinforcing stimuli on associative learning in Lymnaea stagnalis. Zool Sci 13: $803-812$

Kojima S, Nakamura H, Nagayama S, Fujito Y, Ito E (1997) Enhancement of an inhibitory input to the feeding central pattern generator in Lymnaea stagnalis during conditioned taste-aversion learning. Neurosci Lett 230: 179-182

Kojima S, Kobayashi S, Yamanaka M, Sadamoto H, Nakamura H, Fujito Y, Kawai R, Sakakibara M, Ito E (1998) Sensory preconditioning for feeding response in the pond snail, Lymnaea stagnalis. Brain Res 808: 113-115

Lonart G, Südhof TC (1998) Region-specific phosphorylation of rabphilin in mossy fiber nerve terminals of the hippocampus. $J$ Neurosci 18: 634-640

McCrohan CR, Benjamin PR (1980) Synaptic relationships of the cerebral giant cells with motoneurones in the feeding system of Lymnaea stagnalis. J Exp Biol 85: 169-186

Martin KC, Casadio A, Zhu H, E Y, Rose JC, Chen M, Bailey CH, Kandel ER (1997) Synapse-specific, long-term facilitation of Aplysia sensory to motor synapses: a function for local protein synthesis in memory storage. Cell 91: 927-938

McCrohan CR, Audesirk TE (1987) Initiation, maintenance and modification of patterned buccal motor output by the cerebral giant cells of Lymnaea stagnalis. Comp Biochem Physiol 87A: 969977

McCrohan CR, Gillette R (1988) Cyclic AMP-stimulated sodium current in identified feeding neurons of Lymnaea stagnalis. Brain Res 438: 115-123

Montarolo PG, Goelet P, Castellucci VF, Mprgan J, Kandel ER, Schacher S (1986) A critical period for macromolecular synthesis in long-term heterosynaptic facilitation in Aplysia. Science 234: $1249-1254$

Nakamura H, Ito I, Kojima S, Fujito Y, Suzuki H, Ito E (1999a) Histological characterization of lip and tentacle nerves in Lymnaea stagnalis. Neurosci Res 33: 127-136

Nakamura H, Kojima S, Kobayashi S, Ito I, Fujito Y, Suzuki H, Ito E (1999b) Physiological characterization of lip and tentacle nerves in Lymnaea stagnalis. Neurosci Res in press

Nelson TJ, Alkon DL (1990) Specific high molecular weight mRNAs induced by associative learning in Hermissenda. Proc Natl Acad Sci USA 87: 269-273

Ocorr KA, Walters ET, Byrne JH (1985) Associative conditioning analog selectively increases cAMP levels of tail sensory neurons in Aplysia. Proc Natl Acad Sci USA 82: 2548-2552

O'Leary FA, Byrne JH, Cleary LJ (1995) Long-term structural remodeling in Aplysia sensory neurons requires de novo protein synthesis during a critical time period. J Neurosci 15: 3519-3525

Pollock JD, Bernier L, Camardo JS (1985) Serotonin and cyclic adenosine 3':5'-monophosphate modulate the potassium current in tail sensory neurons in pleural ganglion of Aplysia. J Neurosci 5: $1862-1871$

Rose RM, Benjamin PR (1979) The relationship of the central motor pattern of feeding cycle of Lymnaea stagnalis. J Exp Biol 80: $137-163$
Sadamoto H, Hatakeyama D, Kojima S, Fujito Y, Ito E (1998) Histochemical study on the relation between NO-generative neurons and central circuitry for feeding in the pond snail, Lymnaea stagnalis. Neurosci Res 32: 57-63

Schacher S, Castellucci VF, Kandel ER (1988) cAMP evokes longterm facilitation in Aplysia sensory neurons that requires new protein synthesis. Science 240: 1667-1669

Schacher ND, Kandel ER, Montarolo P (1993) cAMP and arachidonic acid stimulate long-term structural and functional changes produced by neurotransmitters in Aplysia sensory neurons. Neuron 10: $1079-1088$

Scholz KP, Byrne JH (1988) Intracellular injection of cAMP induces a long-term reduction of neuronal $\mathrm{K}^{+}$currents. Science 240 : $1664-$ 1666

Siegelbaum SA, Camardo JS, Kandel ER (1982) Serotonin and cyclic AMP close single $\mathrm{K}^{+}$channels in Aplysia sensory neurons. Nature 299: 413-417

Staras K, Kemenes G, Benjamin PR (1998) Pattern-generating role for motoneurons in a rhythmically active neuronal network. $J$ Neurosci 18: 3669-3688

Sugita S, Baxter DA, Byrne JH (1997) Modulation of a cAMP/Protein kinase $A$ cascade by protein kinase $C$ in sensory neurons of Aplysia. J Neurosci 17: 7237-7244

Sweatt JD, Kandel ER (1989) Persistent and transcriptionally-dependent increase in protein phosphorylation in long-term facilitation of Aplysia. Nature 339: 51-54

Tuersley MD and McCrohan CR (1988) Serotonergic modelation of patterned motor output in Lymnaea stagnalis. J Exp Biol 135: 473-486

Wolcourt-Ambakederemo A, Winlow W (1994a) 5-HT receptors on identified Lymnaea neurons in culture: pharmacological characterization of 5- $\mathrm{HT}_{1 \mathrm{~A}}$ receptors. Comp Biochem 107C: 129-141

Wolcourt-Ambakederemo A, Winlow W (1994b) 5-HT receptors on identified Lymnaea neurons in culture: pharmacological characterization of 5- $\mathrm{HT}_{2}$ receptors. Gen Pharmac 25: 1079-1092

Wolcourt-Ambakederemo A, Winlow W (1995) 5-HT receptors on identified Lymnaea neurons in culture: pharmacological characterization of $5-\mathrm{HT}_{3}$ receptors. Gen Pharmac 26: $553-561$

Yamanaka M, Sadamoto H, Hatakeyama D, Nakamura H, Kojima S, Kimura T, Yamashita M, Urano A, Ito E (1999) Developmental changes in conditioned taste aversion in Lymnaea stagnalis. Zool Sci 16: 9-16

Yeoman MS, Kemenes G, Benjamin PR, Elliott CJH (1994) Modulatory role for the serotonergic central giant cells in the feeding system of the snail, Lymnaea. II. photoinactivation. J Neurophysiol 72: 1372-1382

Yeoman MS, Brierley MJ, Benjamin PR (1996) Central pattern generator interneurons are targets for the modulatory serotonergic cerebral giant cells in the feeding system of Lymnaea. J Neurophysiol 75: 11-25

(Received January 11, 1999 / Accepted March 23, 1999) 